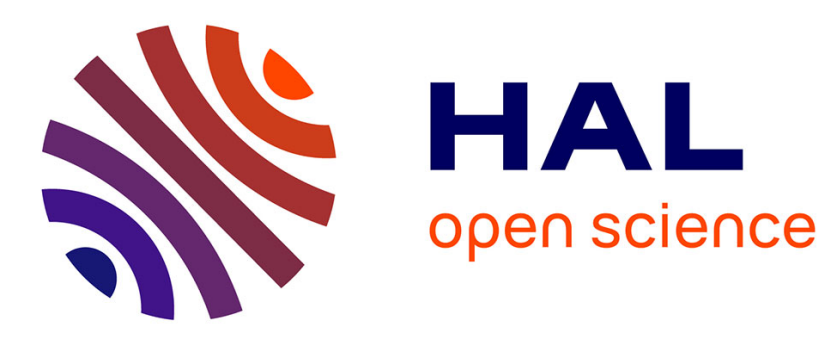

\title{
Analysing Audible Ecosystems and Emergent Sound Structures in Di Scipio's Music
}

\author{
Renaud Meric, Makis Solomos
}

\section{To cite this version:}

Renaud Meric, Makis Solomos. Analysing Audible Ecosystems and Emergent Sound Structures in Di Scipio's Music. Contemporary Music Review, 2014, 10.1080/07494467.2014.906690 . hal-01202885

\section{HAL Id: hal-01202885 \\ https://hal.science/hal-01202885}

Submitted on 23 Sep 2015

HAL is a multi-disciplinary open access archive for the deposit and dissemination of scientific research documents, whether they are published or not. The documents may come from teaching and research institutions in France or abroad, or from public or private research centers.
L'archive ouverte pluridisciplinaire HAL, est destinée au dépôt et à la diffusion de documents scientifiques de niveau recherche, publiés ou non, émanant des établissements d'enseignement et de recherche français ou étrangers, des laboratoires publics ou privés. 


\title{
Analysing Audible Ecosystems and Emergent Sound Structures in Di Scipio's Music
}

\author{
Renaud Meric, Makis Solomos
}

This paper discusses the possibility of analysing (in the musical meaning of the word) Agostino Di Scipio's “audible ecosystems”. A first part is focused on the notion of audible ecosystem and its theoretical counterpart, the idea of emergent sound structures. With this last idea, high levels of a musical work (for instance, the macroform itself) appear as an emergence from lower levels. As for the notion of audible ecosystem-analyzed here through the live electronics solos named Audible Ecosystemics - it is achieved through interaction between the performer, the electronics and the environment. Then, the paper tries to define an analytic image of the resultant sounds of the audible ecosystems. To do so, we use the concept of imprint (empreinte in French) as it is analyzed by Georges Didi-Huberman. Then, we go back to musical analysis and argue that a musical analysis of Agostino Di Scipio's audible ecosystems involves an analysis of the relationships between what we have listened to, what we can only imagine and the compositional techniques. Before concluding, the article shows an example of this way of analyzing by taking a sample at random from the piece Audible Ecosystemics $3 b$.

Keywords: Agostino Di Scipio, emergence, ecosystem, feedback, space.

\section{Introduction}

This paper focuses on Agostino Di Scipio's compositional and theoretical research on audible ecosystems and emergent sound structures (Di Scipio, 2003, 2005a, 2005b, 2008, 2011; Solomos, 2005; Meric, 2008; Döbereiner, 2014; Green, 2014; Schröder, 2014) and poses the question "How can (musical) analysis deal with such research?"

While composing with an ecosystemic approach, the composer creates an audio system that interacts with the environment (i.e. space). This space, in which and from which music emerges, is also the listener's space. Thus what emerges is the result of a confrontation between the listener's cognitive system and the audio system used in the musical work. The emergent sound is difficult to define: its general outline is unpredictable and unstable; it is dependent on a dynamic musical space, which is constructed by active listening and an active audio system simultaneously. This new musical paradigm, which is related to the notion of complexity, challenges musical analysis. How is it possible to analyse structures that have no independent existence, not only as musical material but also apart from the listener and the space in which they take place?

Analysing these structures means focussing on the ephemeral moment in which music emerges in the interaction between the listener and the product of the audio system inside a specific space. To develop the tools for such a musical analysis, we will call on phenomenology (Merleau-Ponty, 1964), which, when related to music, asks the more general questions, "What emerges from listening?" "What phenomena does listening create?" A simple and short answer to these two relatively similar questions could be: (musical) sound. 
But if we examine the birth of sound closely, in its emergence as a structure, then new questions arise: "What are the spatial and temporal limits of this emergence?" "From what is it constucted?" "How does it appear as a structure?" Phenomenology shows that musical analysis cannot limit itself to objective structures (sound, form, etc.), an idea that is helpful in comprehending the sound structures we have to deal with in Di Scipio's music. Furthermore, we will suggest that, in reality, we don't listen to sound but to its own "imprint" (empreinte), in the sense of the word developed by Georges Didi-Huberman (2008).

But let's first understand the notions of emergent sound structures and audible ecosystems.

\section{Emergent sound structures and audible ecosystems}

\subsection{Emergent sound structures}

Analysing Xenakis's hypothesis (Xenakis, 1992: 103) of an (auto-)creation of "higher order sonorities" in Analogique A et B (1958-1959, for nine strings and tape), a composition that uses the granular paradigm, Di Scipio makes a small shift in Xenakis's concept: "Today cognitive scientists and epistemologists would probably describe the hypothesis of 2nd-order sonorities as a question of emergent properties of sound structure" (Di Scipio, 2001: 72). The question of emergent structures can be formulated as follows: "In this case [concerning Analogique B], the distinction can hardly be made between a model of musical articulation and a model of sound design, insofar as the composer's action is meant to let the musical (macro-level) structure emerge from sound itself and its internal organization (micro-level)" (Di Scipio, 1997: 165). Whereas the "failure" of Analogique to create second-order sonorities is probably viewed by Xenakis as a failure of the grain's fusion, Di Scipio views this failure as one of emergence and attributes it to the limits of Xenakis's mathematical tools: "One may ask whether the stochastic does really provide as good a means for higher-order sonorities to emerge from a ground-level pattern of minimal sonic units" (Di Scipio, 2001: 73, 79). And, in fact, in his own music, Di Scipio opted for complex dynamic systems: "Chaos and the dynamics of complex systems, as accessible with iterated numerical processes, represented for me a way to compose small sonic units such that a higher-level sonority would manifest itself in the process" (Di Scipio in Anderson, 2005). These systems enable him "[to] exploit [... a large] palette of grain arrangements, ranging from random to more patterned textures, across a variety of other behaviours" (Di Scipio in Anderson, 2005). Thus, unlike other composers who worked with the help of the granular paradigm, such as Xenakis and Horacio Vaggione (Solomos, 2013: 396-414), Di Scipio tends to get rid of everything that might have been composed as a macroform design. For instance, in his music, there are no dramatic gestures, 
no dramatic intentions. In one of his first articles (Di Scipio, 1994), he elaborated a "theory of sonological emergence", whereby form (macroform) is viewed as "a process of timbre formation" (Di Scipio, 1994: 205).

The idea of emergent sound structures is related to the elaboration of a sub-symbolic theory. In the "theory of sonological emergence", the emergence of a higher level should happen through grains and samples, neither of which are symbols, as they are located on a low level (cf. Di Scipio, 1994: 207). With composed interactions (cf. infra), Di Scipio puts the interaction at the signal level: all the information exchanges have a sonic nature (cf. Di Scipio, 2003: 272). We can draw a parallel between this strategy and the model of emergence in cognitive science. To the question "What is cognition?" the "computationalist" model answers "Data processing: the manipulation of symbols from rules" (Varela, 1996: 42), while the emergence model answers "The emergence of global states in a network of simple components" (Varela, 1996: 77). Regarding music, the issue at stake here is as follows: if we want the higher level (the macroform) to appear as an emergence and not as an independent construction, we have to work only at the lower level, abandoning the intermediate level, which is the level of symbols.

\subsection{Audible ecosystems}

According to emergence theory, the emergence of sound structures is possible because of the fact that the composer develops systems (in the sense of cybernetics) close to living systems, which are characterized by their capacity for auto-organization:

The passage of a system or process from a given structural organization to a new state of order which is recognized as a function of the qualitative properties of the former, is what we call here a phenomenon of emergence [...]. Similar phenomena can be described with rules of morphostasis (conservation of coherence, identity) and morphogenesis (dynamical behaviour, change), which together capture the main peculiarity of social and living systems: self-organization. (Di Scipio, 1994: 206)

To make sure that the system is auto-organized, Di Scipio uses "circular causality" (Di Scipio in Anderson, 2005), which extends the idea of feedback. For instance, in Due di Uno (2003, for violin, piccolo recorder and adaptive DSP), the instrumental sounds, which are electronically transformed, are also used as input for controlling these transformations (cf. Di Scipio, 2005a). As a result of this circular causality, Di Scipio redefines the usual notion in live electronics of "interaction" (cf. Di Scipio, 2003). According to the usual notion, interaction operates as an information flow: a sound source is transformed. The system is therefore not very interactive. For Di Scipio, the process of composing itself might be the action of composing interactions. Thus, 
a principal aim would be to create a dynamical system exhibiting an adaptive behaviour to the surrounding external conditions, and capable of interfering with the external conditions themselves. [...] A kind of self-organization is thus achieved [...]. Here, 'interaction' is a structural element for something like a 'system' to emerge [...]. System interactions, then, would be only indirectly implemented, the by-products of carefully planned-out interdependencies among system components [...]. This is a substantial move from interactive music composing to composing musical interactions, and perhaps more precisely it should be described as a shift from creating wanted sounds via interactive means, towards creating wanted interactions having audible traces. (Di Scipio, 2003: 271)

We could say that for Di Scipio, the notion of process is decisive: the process is more important than the result-and also more important than its origin.

But interaction also happens with the acoustic environment: another important element in Di Scipio's approach is the idea of “ecosystem". In the set of pieces called Audible Ecosystemics (2002-2005, live electronics solos; Di Scipio, 2005b), which offers implementations of composed interactions (cf. figure 1), the ecosystem is a triangular interaction between the musician, the DSP computer and the sonic ambience (cf. Di Scipio, 2003: 272-275). This idea has noise play an important role. To simplify, we would say that in Di Scipio's music, noise is neither disturbance (as in traditional music), nor sonic material (as in modern music). It is one of the agents of the interaction since it is produced by the concrete place wherein the interaction occurs: it is part of the system. In Audible Ecosystemics, "the role of noise is crucial [...]. Noise is the medium itself where a sound-generating system is situated, strictly speaking, its ambience. In addition, noise is the energy supply by which a self-organizing system can maintain itself and develop" (Di Scipio, 2003: 271).
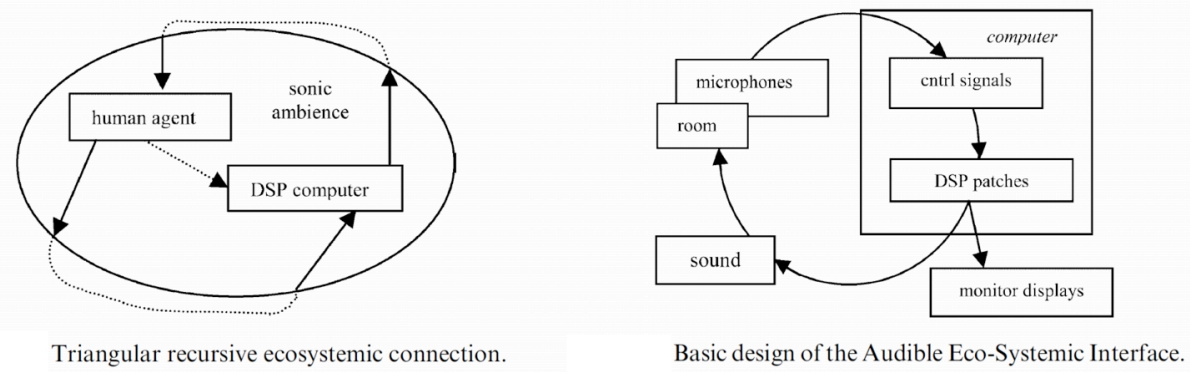

Figure 1. Agostino Di Scipio (2003: 272): composed interactions for the Audible Eco-Systemic Interface.

\section{An analytic image}

Emergent sound structures, processes and composed interactions, sub-symbolic strategy, ecosystems: all these elements converge. What is music, asks Di Scipio? Is it a sonic result? 
No, because what must be composed is the process and not the result. Is it a voluntary gesture enacted by one or more humans, the composer, the performer or the listener? Not only, because the environment is also a component. Is it a language (whereof the mediation of the symbol creates a dichotomy between matter and meaning)? No. "I am interested in composing desirable interactions among available elements or components, such that the music is heard as the empirical epiphenomenon of that network of interactions, not as an abstract discourse written by me and diligently spoken by others" (Di Scipio, 2005a: 385). For musical analysis, the question is "How should we analyze Agostino Di Scipio's music?"

Indeed, if the process is more important than the result, then classical analysis, which searches for objective sound structures, is not possible. With Audible Ecosystemics, the only result we may have is subjective and ephemeral listening. What "I" have listened to cannot reappear. This assertion is not a purely solipsistic idea but stems from the fact that we take into consideration the emergent particularity of these musical works. In Audible Ecosystemics, the ecosystem is not only a triangular interaction between the musician, the DSP computer and the sonic ambience; it also includes a close interaction between the work and the listener. Both are components of the ecosystem:

\footnotetext{
Listeners are a very special kind of external observer or hearer, because their mere physical presence in the room acts as an element of acoustical absorption. Hence they are rather an internal component of the ecosystemic dynamics. As is well-known, audience-less rehearsals are far from replicating the real performance context, and even a relatively small audience can deeply modify the room response. In the AESI [audible eco-systemic interface] project, this is not considered as a problem, nor an element irrelevant to the music: changes in the ambience will reveal peculiar changes in the overall ecosystemic dynamics, and therefore in the audible results themselves. (Di Scipio, 2003: 274)
}

The listener and the work are in the same space-and-time domain: it is not possible to delimit a special space domain and a special time domain for music (cf. Meric, 2008). This point is crucial since making this kind of demarcation is usually the first step for musical analysis. In other words, the analyst begins by choosing a point of view and by delimiting what he considers to be objective from what he considers to be subjective. Thus the work obtains a specific space and a specific time, as if it were a specific world, an entity with its own structure.

From this viewpoint, the work is nothing but an image. Indeed, musical analysis of a work can be considered as image analysis. The analyst uses various tools to describe, to dissect, to simplify. He does not directly observe the musical work or what he is listening to but rather the image he has built. What does that mean? When the analyst translates the musical work into an image, he dreams up a static and universal entity. Anton Ehrenzweig's explanation of the opposition between "syncretistic vision" and "analytical vision" may account for this situation: 
The undifferentiated structure of primary-process phantasy corresponds to the primitive still undifferentiated structure of the child's vision of the world. Piaget has given currency to the term 'syncretistic' vision as the distinctive quality of children's vision and of child art. Syncretism also involves the concept of undifferentiation. Around the eighth year of life a drastic change sets in children's art, at least in Western Civilization. While the infant experiments boldly with form and colour in representing all sorts of objects, the older child begins to analyse these shapes by matching them against the art of the adult which he finds in magazines, books and pictures. [...] What has happened is that the child's vision has ceased to be total and syncretistic and has become analytic instead. The child's more primitive syncretistic vision does not, as the adult's does, differentiate abstract details. The child does not break down the shape of some concrete object into smaller abstract elements and then match the elements of his drawings one by one. His vision is still global and takes in the entire whole which remains undifferentiated as to its component details. (Ehrenzweig, 1967: 56)

The analytical vision must be static. Each element, each detail must have a specific place in time and space, more precisely, in the time and the space of an image. There is no more room for movement or transformation. Conversely a syncretistic vision implies continuous movement, with no specific limits.

\section{Imprint (empreinte)}

It is difficult to have an analytic perception of Agostino Di Scipio's music. Nothing in his music can be considered as static. In Audible Ecosystemics, there are no specific sounds-no instruments, samples or recordings. For instance, Audible Ecosystemics 3a-Background noise study "starts with 'nothing' [we usually do not pay attention to barely audible sound events; unconsciously, we remove them from our auditory focus] and attempts to make 'something' with it" (Di Scipio, 2005b: 20). In Audible Ecosystemics 3b-Background noise study, with mouth performer 1 , "the source is any small sound involuntarily produced in the mouth and throat" (Di Scipio, 2005b: 20). All these sounds are unpredictable and usually inaudible. They are picked up by two microphones in the room (only one in Background noise study $3 b$, with mouth performer, which is placed inside the mouth or close to the lips), and they are routed-having become numerical signals_-in the DSP unit. Inside this DSP unit, there is no linearity or direct path: the input signals are routed in various ways. Some signals go through different audio signal processing blocks and others go through control signal blocks. Analyzing the DSP network for Audible Ecosystemics allows us to discover a multitude of loops: when it exits a block, a signal is routed many times through other blocks, which control or process the signal, and it can follow various paths. Sooner or later, the

\footnotetext{
1 The new subtitle is: Background noise study, in the vocal tract.
} 
original signal, which was routed through different blocks, will return through the first block (figure 2).

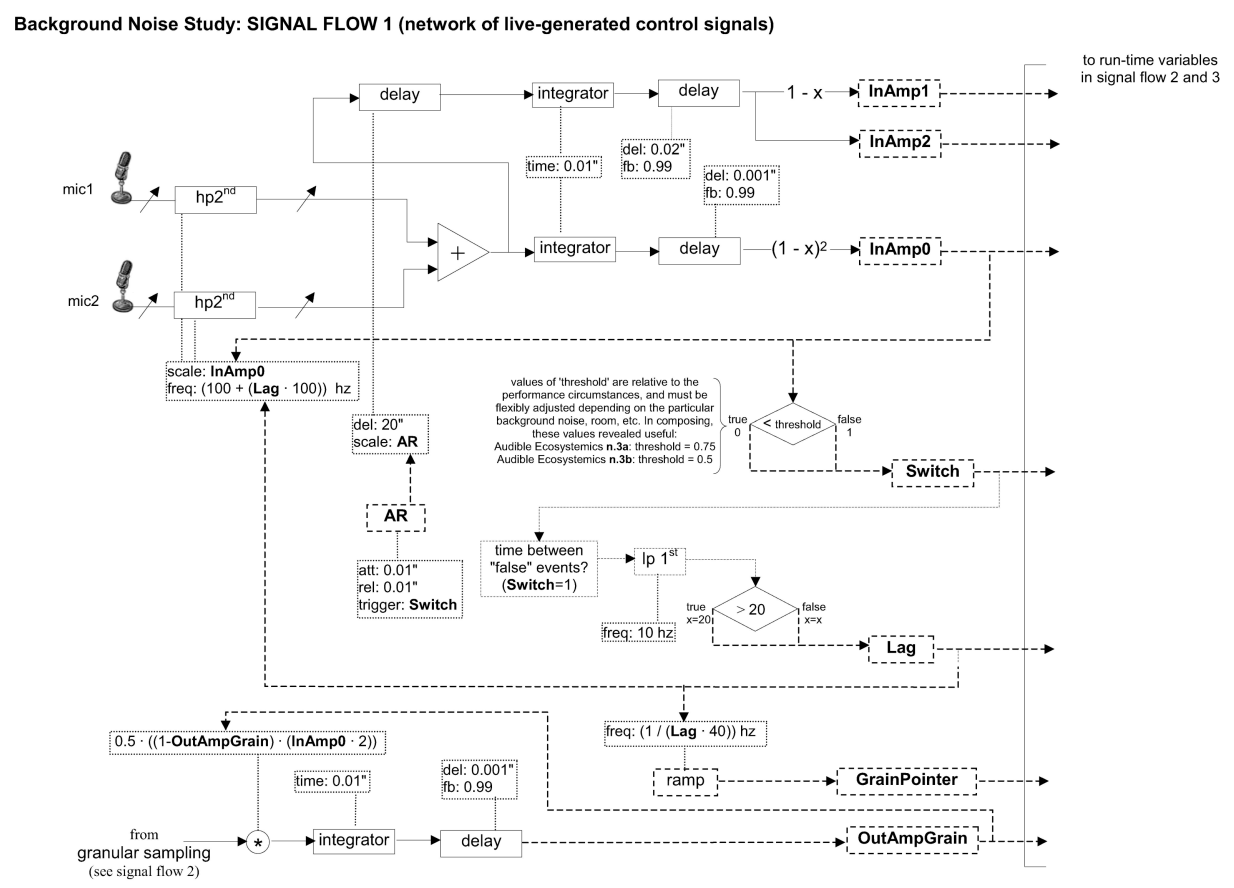

Figure 2. Part of the DSP schema for Audible ecosystemics 3a/3b [Di Scipio, 2004-2005: 6]. On this figure, we can see a loop: [Hp2nd] $\rightarrow$ [integrator] $\rightarrow$ [delay] $\rightarrow$ [InAmp0] $\rightarrow$ [scale: InAmp0 / freq: (100+(lag·100))hz] $\rightarrow$ [Hp2nd].

Every signal—and each part of the signal—can be considered simultaneously as sonic data and as processing data. In other words, the signal is both the material and the gesture that shapes it. The process takes place when a sound emerges from one of the eight loudspeakers: this sound intensifies the background noise (the loudspeakers are turned backward, facing the walls and close to them), which is immediately picked up by the two microphones. We thereby come back to the beginning, making a loop. In conclusion: there is neither and end nor a beginning. Each element is both the end and the beginning of the ecosystem:

Eco-systems are systems whose structure and development cannot exist (let alone be observed or modelled) except in its permanent contact with a medium. There are autonomous (i.e., literally, selfregulating) as their process reflects their own particular internal structure. Yet they cannot be isolated 
from the external word, and cannot achieve their own autonomous function except in close conjunction with a source of information (or energy). To isolate them from the medium is to kill them. (Di Scipio, 2003: 271; italics from the author)

Every part of the ecosystem-inside or outside the DSP - is always a source of energy for the other parts, and always uses the energy that the other parts have processed. In this closed structure, the listener can be considered as an element of the structure too, just like a block in the DSP schema, with an input (the background noise being listening to and that emerges from the loudspeaker) and an output (the modification the listener makes to this background before it is picked up by the microphones).

This description of the situation of the listener might seem simplistic and something of a caricature. However, the "input" of the "listener block" is simply the ordinary answer to the question "What are we listening to?" It is what comes out of the loudspeakers. The traditional identification of "music" with the loudspeaker sound seems inappropriate. Why? A music analyst who begins his investigation with the question "What are we listening to?" is looking for a static image, an image with its own structure (its own space and time). While doing so, the analyst isolates the listener from the ecosystem and considers "sound" merely as musical material, the only "heard" material. However, we have observed that in every step of the ecosystem, sound-more precisely the sonic signal-is both the material and the gesture that shapes it. In Audible Ecosystemics, what we are listening to is not a sound. It is its own "imprint" (empreinte).

To understand the idea of the French word empreinte that we translate here with "imprint", we cite the philosopher and art historian Georges Didi-Huberman. In his book La ressemblance par contact, Didi-Huberman explains the importance of the ichnologist's (the paleolontologist specialized in the study of fossil tracks) work for the art theorist. We could say the same for music and especially for understanding the notion of musical structure, particularly in the case of Di Scipio's ecosystemics structures:

[The ichnologist] has to recognize the complexity of forms; he has to know that shapes are processes, and not only processes' results, that these processes do not have an end, that the image, which is seen, is only the 'anachronistic present' of an uninterrupted play of deformations, alterations, deletions, and 'feedbacks' [revenances] of different kinds. The ichnologist does not have to question what he is looking at as the content iconography or the expression of a mimetic desire. The likeness in every imprint [empreinte] is of another order; in it, nothing can be disentangled; for instance, we cannot separate forms from matter. Here, shapes are substrates; they are dialectical processes of the substrate's modifications caused by an ordinary gesture. The ichnologist knows that what he sees is not a history's single, intangible, point. [...] He knows that shapes are times at work, contradictory 
times entangled in the same image: time of the earth, time of the foot, which in one instant has left its imprint forever" ${ }^{2}$. (Didi-Huberman, 2008: 324-325; our translation)

\section{Back to musical analysis: What is moving...}

If we analyze a musical work as a static image with its own structure, we do not take into consideration what Didi-Huberman says about shapes: "shapes are processes" (and not only the result of processes); "shapes are substrates"; "shapes are times at work, contradictory times entangled in the same image". When we find a structure in a musical work, we must bear in mind that it is merely a fragment of space and time. In Audible Ecosystemics, this assertion is even more obvious: we are listening at the same time to the process and to the sound. The sound (that we are listening to) is a single step of this overall process and, consequently, of the overall structure.

The fundamental question of musical analysis-what are we listening to? - reveals its own limits, as it is looking for a static image with separate space and time. Because the listener is a part of an ecosystemic work, he belongs to the same time, the same space as the work; as the sound. We have to set up the question in another way: "What is moving inside what we are listening to?" When we search for what is moving inside what we are listening to, we are not looking for a result but for a structural process. The listener thus remains inside the ecosystem. The movements or the processes we are listening to are an ephemeral emergence of the entire ecosystem. What emerges can be considered as both objective and subjective: it is not an end of the circular interactions. The movements that we can hear, describe and analyze constitute a small part of the various other movements we can only imagine. For instance, a little click that we hear in Audible Ecosystemics cannot be considered as an object among others or as a detail of a structured image (which would make up the entire work). It is the emergent tip of interweaving, of matching and clashing movements, which are not emerging and which are not audible. Only our imaginations can reach this part of the ecosystemic structure. The click is of no interest without this imaginary and inaudible

\footnotetext{
${ }^{2}$ "[L'ichnologue] est obligé de reconnaître la complexité des formes, il est obligé de savoir que les formes sont des processus, et pas seulement le résultat de processus ; que ces processus, à proprement parler, n'ont pas de fin, que l'image actuellement vue n'est que le 'présent anachronique' d'un jeu ininterrompu de déformations, d'altérations, d'effacements et de 'revenances' de toutes sortes. D'autre part, l'ichnologue n'a nul besoin de questionner ce qu'il regarde comme l'iconographie d'un contenu ou l'expression d'un désir mimétique. La ressemblance offerte dans chaque empreinte est d'un tout autre ordre ; en elle rien ne peut être désintriqué, les formes de la matière par exemple. Car ici, les formes sont des substrats, ou plutôt le processus dialectique des modifications du substrat par un geste quelconque. L'ichnologue, enfin, n'a pas la naïveté de situer ce qu'il voit comme un point unique, intangible de l'histoire. [...]. Il sait donc que les formes sont des temps à l'œuvre, des temps contradictoires intriqués dans la même image : temps de la terre et temps du pied qui, un instant s'y est posé pour toujours".
} 
history. Every sound constitutes a moving empreinte of an underlying moving structure. If we start an analysis with the question "What is moving inside what I am listening to?" instead of "What am I listening to?" we aim to be fully immersed in the genesis of the click. In this way, we do not concentrate on an object-a delimited part of time and space-but on why and how a particular sound emerges simultaneously in music and in the listener's imagination.

To go back to musical analysis, we could start an analysis by searching for the genesis of a sound-in other words, a process-that we can listen to in Audible Ecosystemics. Such a sound may be any sound, which we would grasp at random. It would emerge from a particular process and a particular way of listening, namely an ecosystem. As mentioned above, we should not consider this sound as a delimited and static, structured entity: it appears just once and never emerges again. We should not consider it as being more than a particular case, an example.

What is moving inside this particular sound? With this question, we do not analyze a "sound"- a sound object—but a moving phenomenon. Thus, one specific sound becomes a complex and multiple phenomenon-a single sound is composed by many movements. When we look at what is moving, we need to define the space that is created by the movements and in which they emerge. We must question the relationships between all these movements. By doing so, we question what we perceive and what we imagine. Little by little, and from movement to movement, this sound, as an entity, vanishes, and we build up an imaginary complex structure. In this imaginary complex structure, listening is not the result, the aim or the end of musical analysis but rather the beginning. In Agostino Di Scipio's Audible Ecosystemics, structure is an underlying phenomenon; strictly speaking, it is inaudible and invisible. The question "What is moving inside this particular sound?" allows us to partially reveal a structure.

This question also allows us to tackle the musical composition. The answers- the movements we are looking for-concern the composed process as well. We can try to understand why and how this particular sound (this process) emerges. Understanding the composed interactions (cf. Audible Ecosystemics' DSP score) can help us to understand the origin and the form of the specific sound we want to analyze.

Finally, a musical analysis of Agostino Di Scipio's Audible Ecosystemics involves an analysis of the relationships between what we have listened to, what we can only imagine and the compositional techniques.

\section{A sample taken at random}

This paper focuses its analysis on Audible Ecosystemics 3b-Background noise study, with mouth performer (2005), for one performer; two microphones, one in the room and one used by the performer who puts it into his mouth; a DSP unit (Kyma workstation or Pure Data) 
and eight loudspeakers in the room, turned backward, facing the walls. The score is shown in figure 3. (This score is intended for the mouth performer and is followed by detailed instructions.) However, without audio support, we cannot analyze a specific sample-for instance, a one-second clearly-delimited sample-extracted at random from the Audible Ecosystemics study. We shall merely outline the potential of such an analysis.

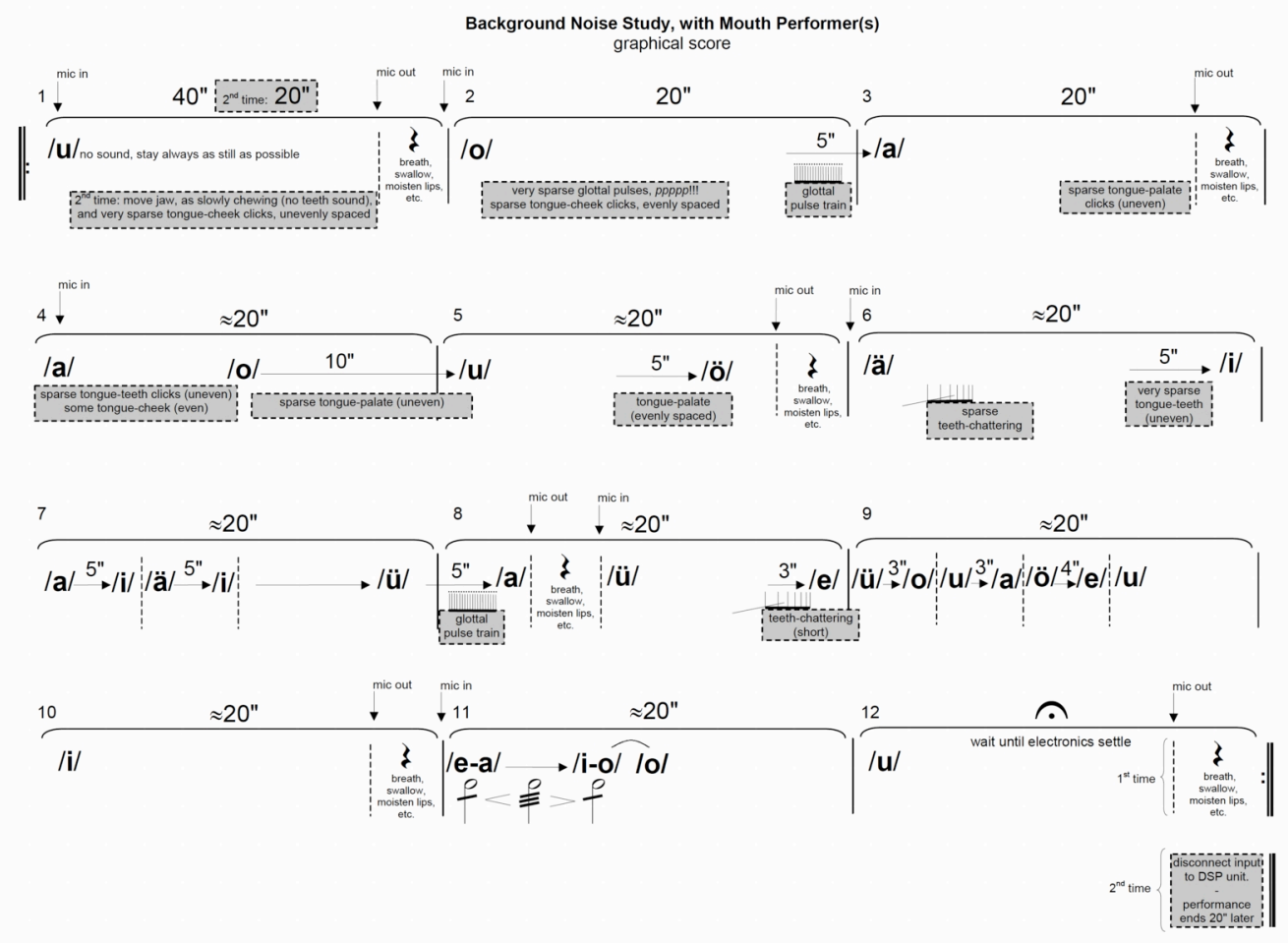

Figure 3. Agostino Di Scipio: Audible Ecosystemics 3b. Background noise study, with mouth performer: score. [Di Scipio, 2004-2005: 11].

A short sample from this study can be described as several little sounds: a lot of grains, some impacts, several little clicks, different whistles. In spite of this brief description, every sample that we could analyze is very difficult to define and to describe. All the little sounds, which we can listen to in a sample, cannot be well delimited in time and space. All these sounds are manifold and heterogeneous movements: the sample is always a complex interlacing (network) of disparate and multiscale movements. In other words, different time scales and different spaces are entangled in a sample: these time scales and spaces go beyond the sample's limits. 
During the performance, sound is dispatched from eight loudspeakers turned backward, facing the wall. Thus, any sample is heard as a background noise, and any sample emerges from the background noise. For this reason, it is impossible to define a duration for each movement entangled in the sample. For instance, we cannot say when a whistle or a grain appears or when it vanishes because it cannot be disconnected from the moving background noise from which it emerges. The eight loudspeakers, turned backward, facing the wall, indeed create several transverse spatial dynamics and indirect sound: every event is immersed in a dynamic jumble, while remaining an active element of it. Every single sound is not an independent entity (an object): it is a spatial and temporal link. For this reason, each sound or each event is directionless. In other words, every little sound heard in a sample can be considered simultaneously as a movement, a single part of larger movements and a combination of movements.

What is the root of these movements we can listen to in a sample? A part of them is emitted directly from the ambient and barely audible background noise (audience noise, airconditioning, etc.); another part of them arises from the amplified background noise and the amplified performer's vocal tract noises, which were recorded 20 seconds earlier. The last part of the sample movement arises from the DSP processing (the recorded background noise is processed in this instance). Thus, when a sample is heard, all these parts are mixed together, compiled and made to clash: each movement from the sample can be one of these parts or the result of the confrontation and the interweaving of these various parts.

When we want to analyze a sample taken from Audible Ecosystemics $3 b$, we are aware that some movements of the sample arise from ambient background noise, but we cannot recognize and delimit them. We also know that some of the movements are an amplification of the previous 20 seconds, which are in themselves an amplification of the previous 20 seconds, and so on. Thus, in the analyzed sample, we can listen to and recognize what happened in the previous 20 seconds, 40 seconds or 60 seconds: some present movementswhich we can listen to in the analyzed sample - take root in these past processes, in these various spatiotemporal strata. In the present space (the sample space), previous spaces are entangled or fossilized (like an "imprint" [empreinte]). Finally, we have to analyze the more complex part, which arises from the DSP processing.

When we focus on the DSP processing, we can first observe that what we are listening to in the sample is spatialized on eight loudspeakers, which are sharing seven outputs (cf. figure 4; in the Audible Ecosystemics 3-Background noise study score, Agostino Di Scipio provides a network of live-generated control signals, the network of audio signals and the loudspeaker assignment schemas; cf. Di Scipio, 2004-2005: 6-8). Two outputs (out 1 and out 2 in figure 4) emit the amplification of the previous 20 seconds. Five other outputs (outs 3, 4, 5,6 , and 7 in figure 4) are dependent on a switch. The latter is activated depending on the input amplitude, and it controls programmed triggers in various ways. But the input amplitude 
is based on erratic sound waves caught by the two microphones; thus we cannot foresee when each output will be activated.

These five unsteady outputs arise from two processes. The first three out of five outputs (outs 3, 4, and 5 in figure 4) send out the input signal depending on different delays and differently programmed triggers. This means that we may recognize some movements among previously heard movements. The last two outputs (out 6 and out 7 in figure 4) send the results from a granular sampling, which reads the mixed signal from the three previous outputs. The granular sampling parameters (grain duration, density, memory pointer, memory pointer jitters) are dependent on shifting inputs (signal amplitude, switch, etc.). Thus we cannot foresee how this granular sampling will react. In every sample, this granular sampling is very important because it forms many grains. It is impossible to hear them independently, and they are combined (with all sounds) as unstable movements.

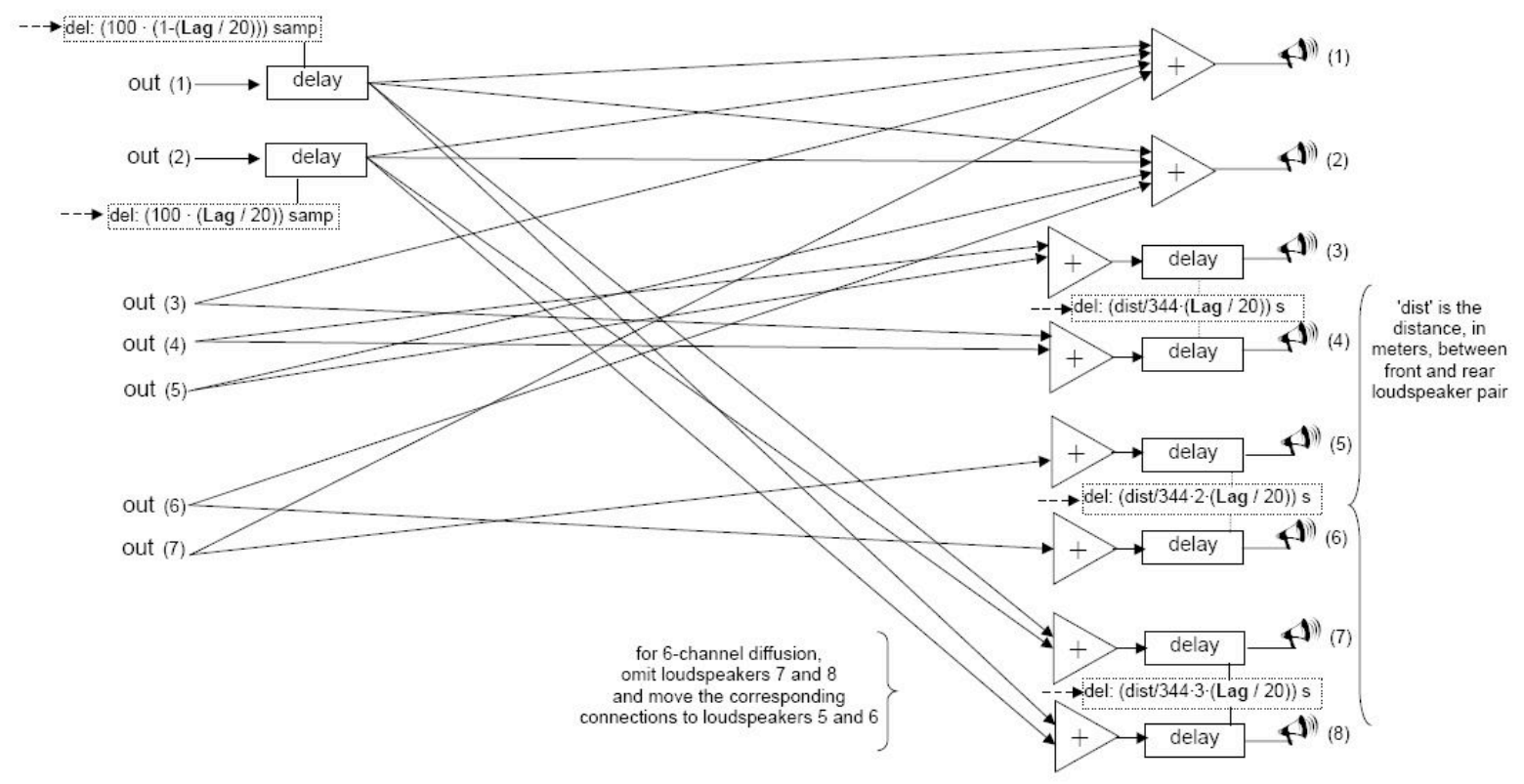

Figure 4. Loudspeakers assignments schema for Audible ecosystemics 3a/3b [Di Scipio, 2004-2005: 8].

\section{Conclusion}

This sketchy analysis, which could be used as a basis for further investigation, displays important features of Di Scipio's Audible Ecosystemics. Each moment (each sample) depends on various aspects, which are comprised of present and previous spaces. None of the samples 
or sound events is ever fully realized or well delimited. In other words, they are never an object (a "sound object") or an image; a point in front of us in time and space. They appear to be a moving articulation: a constantly acting and accomplishing metamorphosis. This short analysis attempts to grasp this complexity, to show the multiplicity of interleaved live roots, and to link various movements: those we can listen to (sounds) and those that are inaudible (DSP data).

Finally, the analysis of Di Scipio's Audible Ecosystemics gives a glimpse of a forgotten aspect of music. More than any other art, music consists not only in a design of (sound) apparitions or creations (temporal and spatial "sound images", which can be analyzed-whereby "analyze" means "breaking down" or "dissecting") but also in a design of disappearings or disintegrations (whereby "analyze" means "rebuilding"). The various processes, the delays and loops that we can observe in the Audible Ecosystemics studies, show not only recurrences but also disappearing spaces. Sound is always both the emergence and the breaking up of many movements.

Agostino Di Scipio's music, especially his Audible Ecosystemics, is a good example of emergent sound structures. In these specific structures, we can never study independently of listening (which is music's subjective side) and the computer processing (its objective side). We should always confront and question "conflicting sides". The notion of movement-and the question "What is moving inside what we are listening to?"-allows us to link these processes and to focus on the instability of the emergent construction.

\section{References}

Anderson, C. (2005). Dynamical Networks of Sonic Interactions. An Interview with Agostino Di Scipio. Computer Music Journal 29(3), 11-28.

Didi-Huberman, G. (2008). La ressemblance par contact. Paris: Éditions de Minuit.

Di Scipio, A. (1994). Formal Processes of Timbre Composition. Challenging the Dualistic Paradigm of Computer Music. Proceedings of the 1994 International Computer Music Conference. San Francisco: International Computer Music Association, 202-208.

Di Scipio, A. (1997). The problem of 2nd-order sonorites in Xenakis' electroacoustic music. Organised Sound 2(3), 165-178.

Di Scipio, A. (1999). Synthesis of environmental sound textures by iterated nonlinear functions. Proceedings of the 2nd COST G-6 Workshop on Digital Audio Effects. Trondheim: NTNU.

Di Scipio, A. (2001). Clarification on Xenakis: the Cybernetics of Stochastic Music. In M. Solomos (Ed.). Présences de / Presences of Iannis Xenakis. Paris: Cdmc, 71-84.

Di Scipio, A. (2003). "Sound is the interface": from interactive to ecosystemic signal processing. Organised Sound 8(3), 269-277. 
Di Scipio, A. (2004-2005). Audible ecosystemics, n3a/Background Noise Study and n3b/Background Noise study, with mouth performer(s) (Instructions and score). Berlin: Berliner Künstlerprogramme des
http://xoomer.alice.it/adiscipi/internal backgroundnoisestudy.htm.

Di Scipio, A. (2005a). Due di Uno. A Composition Dedicated to Horacio Vaggione. In M. Solomos (Ed.), Horacio Vaggione: Composition Music Theory. Contemporary Music Review, 24(4+5), 383-398.

Di Scipio, A. (2005b). CD Hörbare Ökosysteme, live-elektronische Kompositionen 19932005. Berlin: Edition RZ.

Di Scipio, A. (2005c). CD Paysages historiques. Musique électroacoustique 1998-2005. Bourges: Chrysopée électronique-Bourges, LDC 2781130.

Di Scipio, A. (2008). L'émergence du son, le son de l'émergence. In A. Sedes (Ed.), Musique et cognition. Intellectica 48, 221-249.

Di Scipio, A. (2011). Listening to Yourself through the Otherself. On Background Noise Study and other works, Organized Sound, 16(2), 2011, Cambridge University Press.

Döbereiner, L. (2014). Resonances of Subjectivity: Hegel's Concept of Sound and Di Scipio's Audible Ecosystemics, Contemporary Music Review (this issue).

Ehrenzweig, A. (1967). The Hidden Order of Art. A Study in the Psychology of Artistic Imagination. Berkeley: University of California Press.

Green, O. (2014). Audible Ecosystemics as Artefactual Assemblages: Thoughts on Making and Knowing Prompted by Practical Investigation of Di Scipio's Work, Contemporary Music Review (this issue).

Meric, R. (2008). Le bruit de fond est-il un son? À propos d'Écosystèmes audibles $3 a$ d'Agostino Di Scipio. In M. Solomos (Ed.), Musique et bruit. Filigrane 7, Sampzon: Delatour, 197-213.

Merleau-Ponty, M. (1964). Le visible et l'invisible. Paris: Gallimard.

Prominski, M. Ökosysteme hntwerfen. http://www.ila.unihannover.de/fileadmin/theorie_landschaftsarchitektur/documents/

Schröder, J. (2014). Emergence and Emergency. Theoretical and Practical Considerations in Agostino Di Scipio's Works, Contemporary Music Review (this issue).

Solomos, M. (2005). Notes sur Agostino Di Scipio et sur la notion d'émergence. In A. Sedes, H. Vaggione (Ed.) (2005). 12 $2^{e}$ Journées d'Informatique Musicale 2005. Paris: Université Paris 8 - CICM - MSH Paris Nord - Afim, 101-109.

Solomos, M. (2013). De la musique au son. L'émergence du son dans la musique des XXeXXIe siècles. Rennes: Presses Univesitaires de Rennes.

Varela, F. J. (1996). Invitation aux sciences cognitives. Paris: Seuil.

Xenakis, I. (1992). Formalized Music, translated and edited by Sharon Kanach. Stuyvesant (New York): Pendragon Press, 1992. 